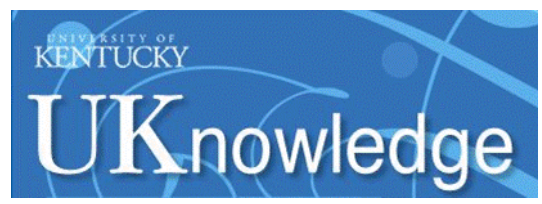

University of Kentucky

UKnowledge

\title{
The Relationship Between Diet, Activity, and Other Factors, and Postpartum Weight Change by Race
}

\author{
Debra J. Boardley \\ University of South Carolina - Columbia, debra.boardley@utoledo.edu \\ Roger G. Sargent \\ University of South Carolina - Columbia, rsargent@mailbox.sc.edu \\ Ann L. Coker \\ University of South Carolina - Columbia, ann.coker@uky.edu \\ James R. Hussey \\ University of South Carolina - Columbia, jhussey@mailbox.sc.edu \\ Patricia A. Sharpe \\ University of South Carolina - Columbia, pasharpe@sc.edu
}

Follow this and additional works at: https://uknowledge.uky.edu/crvaw_facpub

Part of the Obstetrics and Gynecology Commons, and the Public Health Commons

Right click to open a feedback form in a new tab to let us know how this document benefits you.

\section{Repository Citation}

Boardley, Debra J.; Sargent, Roger G.; Coker, Ann L.; Hussey, James R.; and Sharpe, Patricia A., "The Relationship Between Diet, Activity, and Other Factors, and Postpartum Weight Change by Race" (1995). CRVAW Faculty Journal Articles. 146.

https://uknowledge.uky.edu/crvaw_facpub/146

This Article is brought to you for free and open access by the Center for Research on Violence Against Women at UKnowledge. It has been accepted for inclusion in CRVAW Faculty Journal Articles by an authorized administrator of UKnowledge. For more information, please contact UKnowledge@lsv.uky.edu. 


\section{The Relationship Between Diet, Activity, and Other Factors, and Postpartum Weight Change by Race}

\section{Notes/Citation Information}

Published in Obstetrics \& Gynecology, v. 86, no. 5, p. 834-838.

This manuscript provided with permission from the publisher, and also accessible through the journal's website at http://journals.Iww.com/greenjournal/Abstract/1995/11000/

The_Relationship_Between_Diet,_Activity,_and_Other.26.aspx.

Dr. Ann Coker had not been a faculty member of the University of Kentucky at the time of publication. 


\title{
The Relationship Between Diet, Activity, and Other Factors, and Postpartum Weight Change by Race
}

\author{
DEBRA J. BOARDLEY, PhD, ROGER G. SARGENT', PhD, ANN L. COKER, PhD, \\ JAMES R. HUSSEY, PhD, AND PATRICIA A. SHARPE, PhD
}

Objective: To identify the impact of dietary intake and activity level on postpartum weight change.

Methods: White $(n=121)$ and black $(n=224)$ women, $7-12$ months postpartum, participating in the Special Supplemental Feeding Program for Women, Infants, and Children were assessed for dietary intake, activity level, body weight, and other maternal characteristics.

Results: For both black and white women, the most important variables in predicting postpartum weight loss were pre-pregnancy weight, gestational weight gain, parity, and prenatal exercise. After these factors were controlled, race predicted that black women retained $6.4 \mathrm{lb}$ more than white women. These results may be due to the finding that black women reported significantly higher mean energy intake (2039 versus $1552 \mathrm{kcal}, P<.001)$, higher percent fat in diet (41 versus $38 \%, P<.001$ ), and significantly lower amounts of prenatal and postpartum activity.

Conclusion: Higher energy intake and lower activity levels in black postpartum mothers compared with white mothers may contribute to the significantly higher rates of obesity found in black mothers. This study suggests the need for intervention strategies in the prenatal and postpartum periods to help those at risk of retaining weight gained during pregnancy. (Obstet Gynecol 1995;86:834-8)

Obesity, a pervasive and persistent public health problem in the United States, is more common among women than men. ${ }^{1}$ Across subgroups within the population, not all women are equally affected; $49 \%$ of black adult women compared with $32 \%$ of white adult women are defined as overweight. ${ }^{1}$ In addition, rates for hypertension, stroke and coronary heart disease,

From the School of Public Health, University of South Carolina, Columbia, South Carolina.

This study was funded by the Special Supplemental Food Program for Women, Infants, and Children (WIC) through the South Carolina Department of Health and Enzirommental Control, Columbia, South Carolina. and non-insulin-dependent diabetes for black women are reported to be 1.5-2.5 times the rates found in white women. ${ }^{2,3}$

A commonly held notion is that weight gain associated with pregnancy contributes to the increased rates of obesity in women. However, the literature is contradictory. ${ }^{4-7}$ Parker and Abrams ${ }^{8}$ concluded from the 1988 National Maternal and Infant Health Survey data, a nationally representative sample of women, that black mothers had about twice the risk of being at least $20 \mathrm{lb}$ heavier postpartum compared with white mothers. The same data set was examined ${ }^{9}$ for weight change in mothers who had prenatal weight gains within the Institute of Medicine's 1990 weight gain guidelines for pregnant women. The results indicated that postpartum weight increased as prenatal weight gain increased and that black women retained more weight than white women with comparable weight gain. The relationship between pregnancy and adiposity changes in young black and white women was examined in a longitudinal study. ${ }^{10}$ Results indicated that there is an association between first pregnancy and increased adiposity for both black and white women, with black women having greater adverse changes in adiposity than white women at each level of parity.

Weight changes associated with pregnancy may contribute to the differing rates of obesity between black and white women ${ }^{8-10}$ Few studies have considered the effects of diet or activity on postpartum weight, a potentially important oversight, because diet, physical activity, and heredity are considered to be the three most important factors in the determination of body weight. ${ }^{11}$ In addition, diet and physical activity level are modifiable factors and are the basis for weight-control efforts.

The purpose of this study was to 1) examine dietary intake and physical activity in a group of postpartum 
women, and 2) explore variables potentially related to weight changes associated with pregnancy and determine whether these factors differ by maternal race. This study extends previous research by the inclusion of diet and activity factors that may be related to weight change.

\section{Materials and Methods}

Postpartum women attending Special Supplemental Food Program for Women, Infants, and Children (WIC) nutrition education classes for their 7-12-month-old infants were the subjects for this study. Data were collected at a WIC clinic over a period of 4 months so that the population would include all eligible postpartum WIC participants at the clinic. Four hundred five consecutive women attending the classes were invited and agreed to participate in the study.

For data analysis, subjects were excluded if they were younger than 18 years old, were pregnant with a subsequent pregnancy, had a neonate who weighed less than $5.5 \mathrm{lb}$, or reported their race as other than black or white; 48 women were excluded by these criteria. In addition, 11 women were excluded because they failed to complete the entire survey. During multiple linear regression analysis, one subject was excluded because her reported weight change from before to after pregnancy was more than $100 \mathrm{lb}$ and the data point was an outlier. The final model was also run with the outlier, resulting in no change in significance. The final data set consisted of 345 white $(n=121)$ and black $(n=224)$ postpartum women.

The survey instrument was a paper and pencil, self-administered questionnaire. Information regarding usual dietary intake was assessed using the optically scannable version of the food frequency questionnaire developed and used by the National Cancer Institute. This food frequency questionnaire is used for epidemiologic and clinical use to provide information about an individual's usual dietary intake. ${ }^{12}$ Although all diet recall methods are subject to questions of validity, the food frequency questionnaire has been validated in a range of population groups, including those similar to the subjects in this study. ${ }^{13}$

Participants were instructed to complete the food history according to how they have eaten since the delivery of their infant. We used the software HHHQDIETSYS (version 3.0; National Cancer Institute, Bethesda, MD) to analyze the scanned data. Total energy intake and percentage of fat in the diet were used as independent variables.

Information about usual physical activity level both during and after pregnancy was collected using a questionnaire adapted from an instrument used previ- ously to collect activity data from women. ${ }^{14}$ For each activity reported, the number of times per week (frequency), the length of time engaged in the activity (duration), and an exertion rating (intensity) were multiplied together, and all activities were summed to produce an activity score that was used as an independent variable.

The instrument included questions about the infant's age and birth weight, mother's return to work, breastand formula feeding, mother's pre-pregnancy weight, mother's weight at delivery, parity, smoking behavior, and the use of oral contraceptives. The instrument was pretested in a group of women attending a similar WIC clinic. The entire questionnaire took 30-35 minutes to complete and was administered as part of the WICrequired nutrition class, which usually lasted 45-60 minutes. Consequently, the assessment did not impose an additional burden on the study group. After administration and collection of the survey instrument, subjects were measured for height and weight. Weight was measured without shoes or extraneous clothing (eg, sweaters or jackets) using a standard clinical scale that was zero balanced before each assessment period.

The SAS software package (SAS Institute, Cary, NC) was used to perform all statistical analysis. Student $t$ test for unpaired observations was used for comparisons of continuous variables between races. Other univariate analyses were done using analysis of variance. Pearson product-moment correlation coefficient was used to measure association. Chi-square test was used for comparisons of categorical variables.

For multivariate analysis, the dependent variable was weight change, defined as the measured current weight minus the mother's self-reported pre-pregnancy weight. Multiple linear regression was used to develop the models relating weight change to energy intake, physical activity level, and other variables of interest. Models for the multivariate analysis were based on a priori hypotheses of important variables thought to affect weight change. Variables and possible interactions were entered into the model, and stepwise procedure with backward elimination was used to drop nonsignificant terms from the model. An alpha level of .05 was used to determine statistical significance.

\section{Results}

The mean ages for white and black subjects were 25.0 and 26.2 years, respectively. Although mean height did not differ, current weight (pounds) differed significantly (white $146.9 \pm 36.5 \mathrm{lb}$ and black $162.9 \pm 44.3 \mathrm{lb}, P<$ .001). Neither the birth weight of the neonate nor the age of the mother at first childbirth differed signifi- 
Table 1. Demographic and Anthropometric Characteristics

\begin{tabular}{lccl}
\hline & $\begin{array}{c}\text { White women } \\
(n=121)\end{array}$ & $\begin{array}{c}\text { Blark women } \\
(n=224)\end{array}$ & $P^{*}$ \\
\hline Age (y) & $25.0 \pm 4.9$ & $26.2 \pm 6.0$ & .02 \\
Height (in) & $64.3 \pm 2.5$ & $64.4 \pm 2.5$ & .64 \\
Current weight (lb) & $146.9 \pm 36.5$ & $162.6 \pm 44.3$ & .001 \\
Age at first childbirth (y) & $21.9 \pm 4.7$ & $21.7 \pm 4.6$ & .6 \\
Education (y) & $12.4 \pm 1.7$ & $12.9 \pm 1.6$ & .007 \\
Birth weight of neonate (lb) & $7.3 \pm 0.9$ & $7.2 \pm 1.0$ & .31 \\
\hline
\end{tabular}

Data are presented as mean \pm standard deviation.

* $t$ test for racial difference.

cantly. Black women did report more years of education than the white women (Table 1).

The distributions of white and black females in the categories of breast-feeding, mother returning to work, maternal marital status, and maternal smoking differed significantly. More black mothers returned to work after giving birth. White women were more likely to breast-feed ( 43.8 versus $21.9 \%$ ). Among white women, $7.4 \%$ reported exclusive breast-feeding and $36.4 \%$ breast-fed and supplemented with formula; for black women, $2.2 \%$ reported exclusive breast-feeding and $19.6 \%$ breast-fed with formula supplementation. For mothers who did breast-feed, however, duration rates were similar; white women reported breast-feeding 3.3 \pm 2.1 months, whereas black women reported $3.2 \pm 2.2$ months. White women were more likely to be married and were more likely to smoke cigarettes. In both groups, about half were primiparous (white $49.6 \%$ versus black $48.7 \%$ ) (Table 2 ).

Black women reported higher pre-pregnancy weight (white $140.1 \pm 33.5 \mathrm{lb}$ versus black $149.3 \pm 39.4 \mathrm{lb}$ ). The difference in current postpartum body weight was even greater, with white women weighing $146.9 \pm 36.5 \mathrm{lb}$ compared with $162.6 \pm 44.3 \mathrm{lb}$ for black women. Both groups reported similar gestational weight gain (Table 3 ).

There were significant differences in diet and physical

Table 2. Maternal Demographic Characteristics

\begin{tabular}{lccc}
\hline & $\begin{array}{c}\text { White women } \\
(n=121)\end{array}$ & $\begin{array}{c}\text { Black women } \\
(n=224)\end{array}$ & $p^{*}$ \\
\hline Return to work & $64(52.9 \%)$ & $145(64.7 \%)$ & .03 \\
Brcast-fecding & $53(43.8 \%)$ & $49(21.9 \%)$ & .001 \\
Smoking & $39(32.2 \%)$ & $26(11.6 \%)$ & .001 \\
Dieting & $37(30.6 \%)$ & $62(27.7 \%)$ & .57 \\
Married & $86(71 \%)$ & $62(27.7 \%)$ & .001 \\
Primipara & $60(49.6 \%)$ & $109(48.7 \%)$ & .12 \\
\hline
\end{tabular}

Return to work was mother reporting starting or re-entering work in the postpartum period. Breast-feeding includes all women who reported breast-feeding for longer than 1 week. Smoking includes those mothers who are currently smoking. Dieting behavior is taken from the question, "Do you consider yourself to be dieting now?" Marital stalus is at the time of the survey.

${ }^{*}$ Chi-square test for racial differences.
Table 3. Calories, Percentage of Fat, and Weight

\begin{tabular}{lccc}
\hline & $\begin{array}{c}\text { White women } \\
(n=121)\end{array}$ & $\begin{array}{c}\text { Black women } \\
(n=224)\end{array}$ & $P^{*}$ \\
\hline Calories & $1551.7 \pm 626.1$ & $2039.4 \pm 947.3$ & .001 \\
\% fat in diet & $37.5 \pm 8.5$ & $40.7 \pm 5.9$ & .001 \\
Prenatal activity score & $673.4 \pm 566$ & $476.4 \pm 544$ & .002 \\
Postnatal activity score & $735.0 \pm 582$ & $603.0 \pm 589.2$ & .047 \\
Pre-pregnancy weight (lb) & $140.1 \pm 33.5$ & $149.3 \pm 39.4$ & .02 \\
Gestational weight gain (lb) & $31.6 \pm 12.9$ & $31.1 \pm 11.9$ & .72 \\
Current weight (lb) & $146.9 \pm 36.5$ & $162.6 \pm 44.3$ & .001 \\
\hline
\end{tabular}

Activity scores were derived by multiplying the reported activity by frequency, duration, and intensity and summing reported activities.

Data are presented as mean \pm standard deviation.

$* t$ test for racial differences.

activity. The mean daily caloric intake was greater for black women than for white women $(2039 \pm 947$ versus $1552 \pm 626 \mathrm{kcal}$, respectively; $P<.001$ ). In addition, black women reported a higher percentage of fat in their diets. White women reported significantly higher prenatal and postpartum physical activity scores (Table 3).

Next, multiple linear regression modeling was performed to explore the factors that predict postpartum weight change. Twenty-seven percent of the variance in weight change was explained by six independent variables: pre-pregnancy weight, gestational weight gain, parity (primiparous or multiparous), race, prenatal physical activity score, and race by prenatal physical activity (an interaction term) (Table 4). Using the model to adjust for the aforementioned factors, race predicted a 6.4-lb increase in weight change for black mothers.

Because race was a significant variable throughout the model-building process, race analysis was performed. Again, all of the variables were entered into the multiple linear regression model and nonsignificant factors were eliminated with stepwise procedure. However, the same variables were most significant in pre-

Table 4. Variables Predicting Weight Change*: Results of Multiple Linear Regression

\begin{tabular}{lccc}
\hline \multicolumn{1}{c}{ Independent variables } & $\begin{array}{c}\text { Index } \\
\text { estimate }\end{array}$ & $\begin{array}{c}\text { Standard } \\
\text { error }\end{array}$ & $P$ \\
\hline Pre-pregnancy weight & 0.0797 & 0.0167 & .001 \\
Gestational weight gain & 0.4362 & 0.0511 & .001 \\
Parity & 3.201 & 1.249 & .011 \\
Race & 9.776 & 1.917 & .001 \\
Prenatal activity score & 0.0038 & 0.0018 & .042 \\
Race by prenatal activity & -0.0066 & 0.0023 & .005 \\
\multicolumn{1}{l}{ score } & & & \\
\hline
\end{tabular}

Pre-pregnancy weight is the self-reported average weight before pregnancy. Parity is a dummy variable in which primiparous $=0$ and multiparous $=1$. Race is a dummy variable in which white $=0$ and black $=1$

$n=345 ; R^{2}=0.2672$.

"Weight change is current measured weight minus preconceptual weight. 
dicting postpartum weight change in both racial groups.

\section{Discussion}

The findings of this study agree with other recent studies $^{8-10}$ that report that black women retain more weight after pregnancy than do white women. We found that black women reported more total calories, a diet with a higher percentage of the calories from fat, and less physical activity prenatally and postpartum than did their white counterparts.

As in a previous report, ${ }^{9}$ black women in our study were significantly heavier postpartum, even though mean gestational weight gains were similar for both black and white women. We conclude that this weight retention is the result of black women failing to lose weight in the postpartum period. These findings are consistent with the study of Kahn et al, ${ }^{15}$ which suggested that nonpostpartum black women are not necessarily at increased risk of gaining weight, but rather they are less likely to lose weight.

Although the association between calorie intake and body weight is not completely understood, energy balance ultimately translates into body weight. In this study, postpartum black women reported calorie intakes that were significantly higher than those of the white women. These results are similar to those of a recent study ${ }^{16}$ that used data from the 1985-1986 Continuing Surveys of Food Intakes by Individuals to examine energy intakes of women before, during, and after pregnancy. ${ }^{16}$ The authors reported that among nonlactating women, white women appeared to decrease their energy intake, whereas black women reported mean increases of $150 \mathrm{kcal}$ over their prepregnancy intake during the first 3 months after delivery, and more than $300 \mathrm{kcal}$ over their prepregnancy intake later in the postpartum year. Thus, there is evidence that black women may be heavicr postpartum because they do not restrict their calorie intake, whereas white women do.

Recently, Ohlin and Rossner ${ }^{17}$ reported that postpartum weight retention correlated negatively with degree of physical activity. The lower physical activity reported in black women in this study concurs with other reports of activity levels in women. ${ }^{18,19}$

The variables predicting weight change were prepregnancy weight, prenatal weight gain, parity, race, prenatal exercise score, and race by prenatal exercise score. As in other studies, ${ }^{8-20}$ women who had higher pre-pregnancy weights retained larger amounts of weight postpartum. With this model, a woman (black or white) who enters pregnancy at 150 rather than $125 \mathrm{lb}$ would be predicted to have a 2 -lb increase in postpar- tum weight that is attributable to the higher prepregnancy weight. Likewise, the model can illustrate the effect of gestational weight gain. A woman (of either race) who gained 40 rather than $30 \mathrm{lb}$ would have $4.4-\mathrm{lb}$ increase in postpartum weight attributable to the increase in gestational weight gain. This concurs with other studies ${ }^{8,9,21}$ reporting that weight gained during pregnancy is a strong predictor of postpartum weight change. The significance of parity (primipara versus multipara) was true for both races and has been reported in other studies. ${ }^{8,21}$ Multiparous women would be predicted to have a $3.2-\mathrm{lb}$ increase in weight retention associated with parity.

Calorie intake was significant in models only when the variable race was not in the model, which can be explained by black women reporting higher calorie intake while also having greater weight change. When analysis included the variable race (or when analysis was race specific), calorie intake was not significant.

The relationship between physical activity and weight change was also considered. Reported postpartum activity was not significant. However, prenatal physical activity was a significant factor. The effect of prenatal physical activity differed by race (and therefore appears in the model as an interaction term). This means that for white women, the more prenatal exercise they reported, the more weight they retained postpartum. The spread between the bottom and top quartile for prenatal activity score was about 500 points, and this would mean an increase in the predicted weight retention of $2 \mathrm{lb}$ for white women that would be associated with this amount of physical activity. For black women, the more prenatal exercise they reported, the less weight change postpartum. The same 500 -point spread would predict a decrease of $1.5 \mathrm{lb}$ attributable to the increase in the prenatal activity score. It has been suggested that obese subjects may overestimate their physical activity. ${ }^{22}$ This may be especially true for white women who perceive more social pressure to be thin. ${ }^{2}$ Thus, overweight white women may be overestimating their prenatal physical activity and obscuring the effect.

Investigations of the association of breast-feeding and postpartum weight loss are equivocal. ${ }^{7,8,21}$ We found breast-feeding was not significant in predicting postpartum weight change.

This study was based on self-report and considered dietary intake and physical activity level in a group of postpartum women. The study group was limited to WIC participants in a metropolitan area in the southeast, and generalizations of the findings should be limited to similar populations. Also, this study measured postpartum weight at only one period of time. Some women may have gained weight during the postpartum period, and it is likely that these women 
may be different than those who failed to lose weight gained during pregnancy.

During pregnancy, many women make marked changes in health norms and behaviors. ${ }^{23}$ Studies have found that prenatal nutritional counseling affects eating behavior during pregnancy ${ }^{24}$ and that an intervention program in the postpartum period facilitates weight loss. ${ }^{25}$ Our results support the need for additional efforts in these areas. In particular, appropriate, culturally specific intervention strategies offered in the prenatal and postpartum periods may have an effect on the prevalence of overweight for at-risk mothers. Prospective studies that would assess diet and activity throughout pregnancy and the postpartum period are recommended to further clarify the effects of diet and activity on the weight of postpartum women.

\section{References}

1. Kuczmarski RJ, Flegal KM, Campbel SM, Johnson CL. Increasing prevalance of overweight among US adults. JAMA 1994;272:20511.

2. Kumanyika S. Obesity in black women. Epidemiol Rev 1987;9:3150.

3. Gillum RF. Overweight and obesity in black women: A review of published data from the National Center for health statistics. J Natl Med Assoc 1987;79:865-71.

4. Forster JL, Bloom E, Sorernsen G, Jeffery R, Prineas MB. Reproductive history and body mass index in black and white women. Prev Med 1986;15:685-91.

5. Baecke JAH, Burema J, Frijters JER, Hautvast JGAJ, van der Wiel-Wetzels WAM. Obesity in young Dutch adults: Sociodemographic variables and body mass index. Int J Obes 1983;7:112.

6. Lanska DS, Lanska MJ, Hartz AJ, Rimm AA. Factors influencing anatomic location of fat tissue in 52,953 women. Int $\mathrm{J}$ Obes 1985;9:29-38

7. Rookus MA, Rokebrand P, Burema J, Deurenberg P. The effect of pregnancy on the body mass index 9 months postpartum in 49 women. Int J Obes 1987;11:609-18.

8. Parker JD, Abrams B. Differences in postpartum weight retention between black and white mothers. Obstet Gynecol 1993;81:768-74.

9. Keppel K, Taffel S. Pregnancy-related weight gain and retention: Implications of the 1990 Institute of Medicine guidelines. Am J Public Health 1993;83:1100-3.

10. Smith DE, Lewis CE, Caveny JL, Perkins LL, Burke GL, Bild DE. Longitudinal changes in adiposity associated with pregnancy. JAMA 1994;271:1747-51.

11. Miller WC, Lindeman AK, Wallace J, Niederpruem M. Diet composition, energy intake, and exercise in relation to body fat in men and women. Am J Clin Nutr 1990;56:426-30.

12. Block G, Hartman AM, Dresser CM, Carroll MD, Gannon J,
Gardner L. A data-based approach to diet questionnaire design and testing. Am J Epidemiol 1986;24:453-69.

13. Block G, Sabar AF. Estimates of nutrient intake from a food frequency questionnaire: The 1987 National Health Interview Survey. J Am Diet Assoc 1992;92:969-77.

14. Jaglal SB, Kreiger N, Darlington G. Past and recent physical activity and risk of hip fracture. Am J Epidemiol 1993;138:107-18.

15. Kahn HS, Williamson DF, Stevens JA. Race and weight change in US women: The roles of socioeconomic factors in young adult women. Am J Public Health 1991;34:139-42.

16. Murphy SP, Abrams BF. Changes in energy intakes during pregnancy and lactation in a national sample of US women. Am J Public Health 1993;83:1161-3.

17. Ohlin A, Rossner S. Trends in eating patterns, physical activity, and socio-demographic factors in relation to postpartum body weight development. Br J Nutr 1994;71:457-70.

18. Wing RR, Kuller LH, Bunker C, et al. Obesity, obesity-related behaviors and coronary heart disease risk factors in black and white premenopausal women. Int J Obes 1989;13:511-9.

19. Burke GL, Savage PJ, Manolio TA, et al. Correlates of obesity in young black and white women: The CARDIA study. Am J Public Health 1992;82:1621-5.

20. Schauberger CW, Rooney BL, Brimer LM. Factors that influence weight loss in the puerperium. Obstet Gynecol 1992;79:424-9.

21. Greene GW, Smiciklas-Wright H, Scholl TO, Karp RJ. Postpartum weight change: How much of the weight gained in pregnancy will be lost after delivery? Obstet Gynecol 1988;71:701-7.

22. Lichtman SW, Pisarska K, Berman ER, et al. Discrepancy between self-reported and actual caloric intake and exercise in obese subjects. N Engl J Med 1992;327:1893-8.

23. Baric L, MacArthur C. Health norms in pregnancy. Br J Prevent Social Med 1977;31:30-8.

24. Orstead C, Arrington D, Kamath SK, Olson R, Kohrs MB. Efficacy of prenatal nutrition counseling: Weight gain, infant birth weight and cost effectiveness. J Am Diet Assoc 1985;85:40-6.

25. Caan B, Horgen DM, Margen S, King JC, Jewel NP. Benefits associated with WIC supplemental feeding during the interpregnancy interval. Am J Clin Nutr 1987;45:29-41.

Address reprint requests to:

Debra J. Boardley, PhD

University of Toledo

Department of Health Education and Human Performance

2801 West Bancroft

Toledo, $\mathrm{OH} 43606$

Received December 20, 1994.

Received in revised form July 14, 1995.

Accepted August 3, 1995.

Copyright (1) 1995 by The American College of Obstetricians and Gynecologists. 